\title{
Ultra-structure characterization of self-etching treated cementum surfaces
}

\author{
Fátima S. Aguilera, Estrella Osorio, Manuel Toledano, Raquel Osorio
}

Department of Dental Materials, School of Dentistry, University of Granada, Granada, Spain

Correspondence:

Avda. de las Fuerzas Armadas 1, $1 B$.

18014 Granada, Spain.

toledano@ugr.es

Received: $25 / 05 / 2010$

Accepted: 13/06/2010

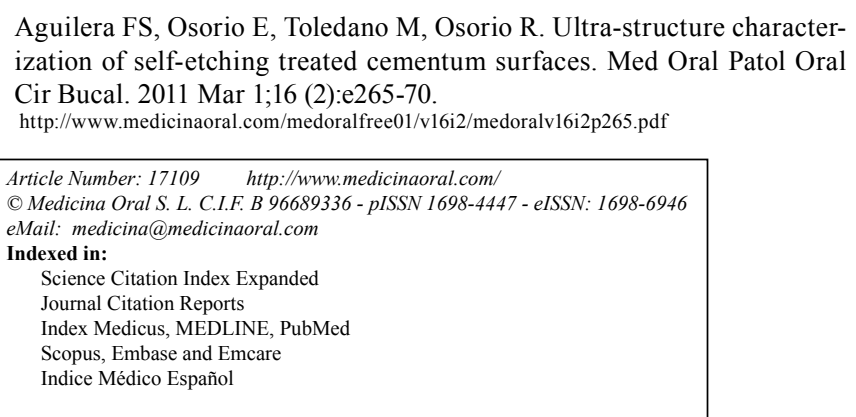

\begin{abstract}
Objectives: to evaluate the effect of different conditioning treatments on surface roughness and topography of dental cementum. Study Design: Extracted human canines were used for the present study. The mesial surface from the cervical third of the roots were ground flat with wet 600 -grit silicon carbide paper. They were polished (up to $1 / 4 \mu \mathrm{m}$ diamond paste) and treated as follows: 1) No treatment, 2) 35\% H3PO4 during $15 \mathrm{~s}$, 3) Clearfil SE Bond primer (SEB), 4) One-Up Bond F (OUB). The adhesive systems were applied following manufacturer's instructions. SEB primer and OUB were removed from surfaces by washing and ultrasonic agitation with ascending ethanol solutions. Digital images of treated surfaces $(5 \times 5$ and $15 \times 15 \mu \mathrm{m})$ were obtained by means of an atomic force microscope (AFM) analysis. The average surface roughness (Ra nanometers) of the scanned areas was assessed. Data were analyzed by ANOVA and SNK multiple comparisons tests $(p<0.05)$. Results: phosphoric acid treatment produced the highest mean roughness value, at all scan sizes. At $5 \times 5 \mu \mathrm{m}$ AFM images, for self-etch adhesive systems no differences in roughness were detected. At $15 \times 15 \mu \mathrm{m}$, when One-Up Bond F was employed the lowest value was obtained. Conclusions: When phosphoric acid treatment was applied, cementum surface roughness increased and a strong demineralization with exposed collagen fibers could be observed.
\end{abstract}

Key words: Cementum, AFM, topography, roughness, phosphoric acid, self-etching.

\section{Introduction}

Developments in adhesive dentistry and in periodontology have enabled tooth lesions to be treated more conservatively, and thus lengthen their lifespan in the oral cavity $(1,2)$. In addition, elderly people are at high risk to have sub-gingival and root caries (3).

Adhesion process depends not only on the adhesive system, but also on the dental substrate (4). Clinically, the margins of many adhesive restorations on the root surface are thought to be positioned in cementum or cervical outer dentin (2). While the bond to dentin is important, that to cementum is also critical to prevent microleakage and bacteria gaining access to the underlying dentin (5). The root cementum has high organic content and predominantly consists of cross-linked collagen structure. This tissue is less hard and more permeable to a variety of materials compared with enamel and dentin (6). Dental cementum has been defined as a composite of non-collagenous proteins and collagen fibrils reinforced with a $65 \%$ on weight inorganic phase (apatite crystals) (7). There are three fundamentally types of cementum: Acellular afibrilar cementum, which covers minor areas of the enamel; acellular extrinsic fiber cementum is mainly found on the cervical and middle portions; and 
cellular intrinsic fiber cementum, that cover the furcations and the apical root portions. (1).

New adhesive systems have been developed in an attempt to obtain a reliable bonding to all tooth substrates (8). Two different approaches are the most frequently used. The etch-and-rinse technique is applied by removing the smear layer with phosphoric acid. This is followed by the application of a primer and an adhesive in two different steps or in a single step. To make this process even simpler and more reliable new adhesives that do not need an acid etching step prior to its application were created, called selfetching adhesive systems. In the self-etching approach, the acid and the primer are combined into one solution to form an acidic monomer (9), prior to the application of a subsequent bonding step. One-step self-etching adhesives have been introduced and contain all components in either a two-bottle set or in a single bottle (10).

Several self-etching systems are available today, but little is known about their ability to interact with the dental cementum. Surface treatments of dental substrate increase the roughness and create microporosities, enhancing the potential for mechanical retention of the adhesive system $(11,12)$. The surface roughness of the cementum can be characterized by topographic measurements (Atomic Force Microscope, AFM), because it provides a real topographical three-dimensional image of a sample surface with vertical resolution from $0.1 \mathrm{~nm}$ and lateral resolution from $0.1 \mathrm{~nm}$ (13).

The objective of this study was to evaluate the effect of different conditioning treatments on surface roughness and topography of dental cementum. The null hypothesis is that the surface treatments do not change the surface roughness and topography of dental cementum.

\section{Materials and Methods}

-Specimen preparation

Twelve canines stored in $0.5 \%$ chloramine $\mathrm{T}$ at $4{ }^{\circ} \mathrm{C}$ for less than one month were employed. The crowns of the teeth and the apical third of the root were perpendicularly removed by using an Accutom-50 (Struers, Copenhagen, Denmark) under copious water irrigation. Flat cementum regions from the mesial surfaces of the cervical root third were used as bonding substrates, after grinding with wet 600 -grit silicon carbide paper with the initiated point 3 $\mathrm{mm}$ below the cement-enamel junction. The presence of cementum was previously verified under a stereomicroscope, using a 40x objective (Olympus/De Trey, Konstanz, Germany). Surfaces were metalographically polished (up to $0.25 \mu \mathrm{m}$ diamond paste). Adhesive systems were applied on the surfaces of the acellular cementum. Composition, manufacturers, and application protocol of the tested adhesives are displayed in table 1 . The $\mathrm{pH}$ of

Table 1. Information about tested adhesive systems.

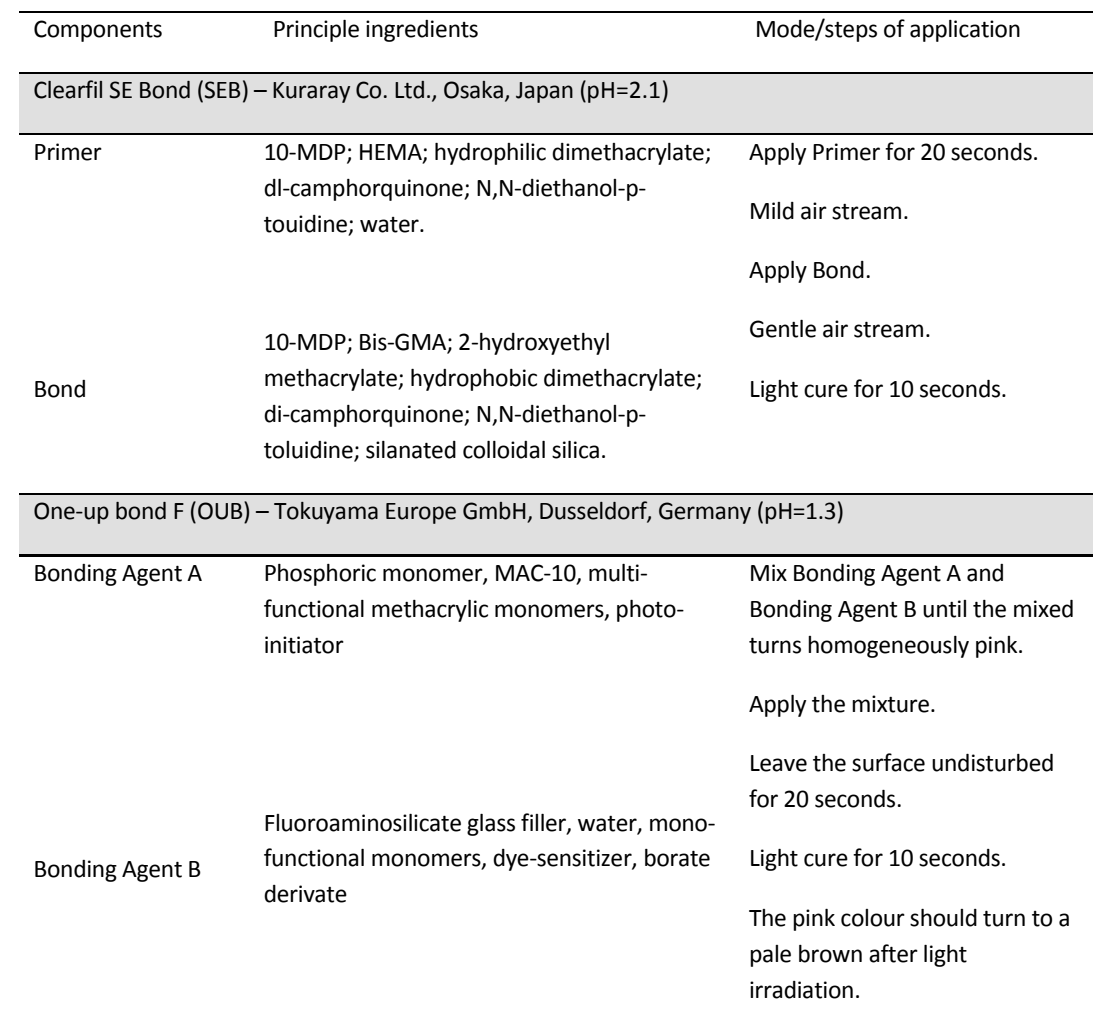

Abbreviations: 10-MDP: 10-methacryloxydecyl dihydrogen phosphate; HEMA: 2-hydroxyethyl methacrylate; Bis-GMA: bis-phenol A diglycidylmethacrylate; MAC-10: Methacryloyloxyalkyl acid phosphate. 
the bonding agents were assessed using $\mathrm{pH}$ indicator strips (Merck KgaA, Darmstadt, Germany).

Roughness analysis by AFM

AFM observation of the conditioned surfaces was performed. The cementum surface treatments were: 1) No treatment, 2) 35\% phosphoric acid (Scotchbond Etchant, 3MESPE, St. Paul, MN, USA) was applied for $15 \mathrm{~s}$ and washed out with distilled water for $30 \mathrm{~s}$, 3) Clearfil SE Bond primer was applied for $20 \mathrm{~s}$, and 4) One-Up Bond F was applied for $20 \mathrm{~s}$. When self-etching adhesives were applied, resin remnants were removed by washing and ultrasonic agitation with different alcohol solutions in ascending series of ethanol $(50 \%, 60 \%, 70 \%$, $80 \%, 90 \%, 96 \%$ and $100 \%$ ) for $1 \mathrm{~min}$ each, and further sonicated in absolute ethanol for $1 \mathrm{~min}$ to dissolve the self-etching primer or adhesive (14). The cementum surfaces, including the phosphoric acid treated surfaces, were rehydrated with distilled water to determine the nanoroughness values.

The topographical features of the surfaces were scanned using an AFM in tapping mode (Multimode Nanoscope IIIa, Digital Instruments, Veeco Metrology group, Santa Barbara, CA, USA). Three digital images $5 \times 5 \mu \mathrm{m}$ and three images $15 \times 15 \mu \mathrm{m}$ under wet conditions were obtained from each specimen. The tapping mode was performed using a 1-10 Ohm-Cm phosphorus (n) dopes Si tip (at $50 \mu \mathrm{m}$ ). Changes in vertical position provided the height of the images, registered as bright and dark regions. A data scale of $1504 \mu \mathrm{m}$ and recorded with a slow scan rate $(0.1 \mathrm{~Hz})$ was employed. For each image, ten randomized boxes (five at $3 \times 3 \mu \mathrm{m}$ and five at $10 \times 10 \mu \mathrm{m}$, respectively) were created to examine the surface roughness of the treated cement $(n=120)$. The topography and the average surface roughness (Ra nanometers) of the scanned areas were qualitatively and quantitatively evaluated, respectively, using Nanoscope Software V7.

-Statistical analysis

Nanoroughness values ( $\mathrm{Ra}-\mathrm{nm}$-) were analyzed with ANOVA and Student Newman Keuls multiple comparisons tests. Statistical significance was set in advance at the 0.05 probability level.

\section{Results}

Mean roughness $(\mathrm{Ra})$ are shown in table 2 . In $5 \times 5 \mu \mathrm{m}$ size images, mean roughness values were higher after using H3PO4 than non-treated surface and when self-etching adhesive systems were employed $(\mathrm{F}=7.30$; $\mathrm{P}<0.01)$. No differences exist between both self-etching adhesives. In $15 \times 15 \mu \mathrm{m}$ images, roughness values increased significantly after using phosphoric acid $(\mathrm{F}=102.70 ; \mathrm{P}<0.0001)$. The $\mathrm{SE}$ Bond primer group was similar to the polished group. The lowest roughness values were obtained when One-Up Bond F was employed. Attained $\mathrm{pH}$ values for each adhesive are displayed in table 1.

Figures 1 and 2 are AFM images of polished and conditioned cementum. Morphological differences are encountered. Height variations in the sample are represented by differences in gray scale, where white represents the highest features and black the lowest features of the scale. The gray level at each position on the surface represents a different depth on the sample surface. The non-treated specimens (Fig. 1a) showed a lamellar pattern corresponding of acellular extrinsic fiber cementum (Notice: A point or locus of periodontal ligament insert can be seen). Figure $1 \mathrm{~b}$ exhibits cementum surface after phosphoric acid etching: the most aggressive removal of the mineral phase is observable. When the cementum surface was treated with SEB primer or OUB (Figs. $1 \mathrm{c}, \mathrm{d}$ ) the surfaces appeared rougher than polished group, but morphological differences were not found between both conditioning treatments. At figure $2 \mathrm{a}$, non-treated specimen at $15 \times 15 \mu \mathrm{m}$, smear layer covers the surface. After H3PO4 etching (Fig. 2b) the cementum surface appeared rougher than the other studied surfaces, and valley-like regions could be observable. When SEB primer was used (Fig. 2c) the image showed a mildly cementum etched surface. Surface after being treated with OUB is shown in figure $2 \mathrm{~d}$ : remaining homogeneous surface of cementum with no lamellar pattern is denoted.

Table 2. Mean (SD) surface roughness (Ra) (nm) after different cementum treatments in $5 \times 5 \mu \mathrm{m}$ and $15 \times 15 \mu \mathrm{m}$ size images $(\mathrm{n}=120)$.

\begin{tabular}{lcc} 
Surface treatment & $5 \times 5 \mu \mathrm{m}$ & $15 \times 15 \mu \mathrm{m}$ \\
\hline No treatment & $32.77(11.5) \mathrm{B}$ & $72.13(7.2) \mathrm{b}$ \\
\hline $35 \% \mathrm{H}_{3} \mathrm{PO}_{4}$ etching & $51.79(15.4) \mathrm{A}$ & $230.78(37.8) \mathrm{a}$ \\
\hline CSEB Primer & $36.02(4.6) \mathrm{B}$ & $61.35(11.4) \mathrm{b}$ \\
\hline OUB & $20.84(7.2) \mathrm{B}$ & $24.87(2.5) \mathrm{c}$ \\
\hline
\end{tabular}




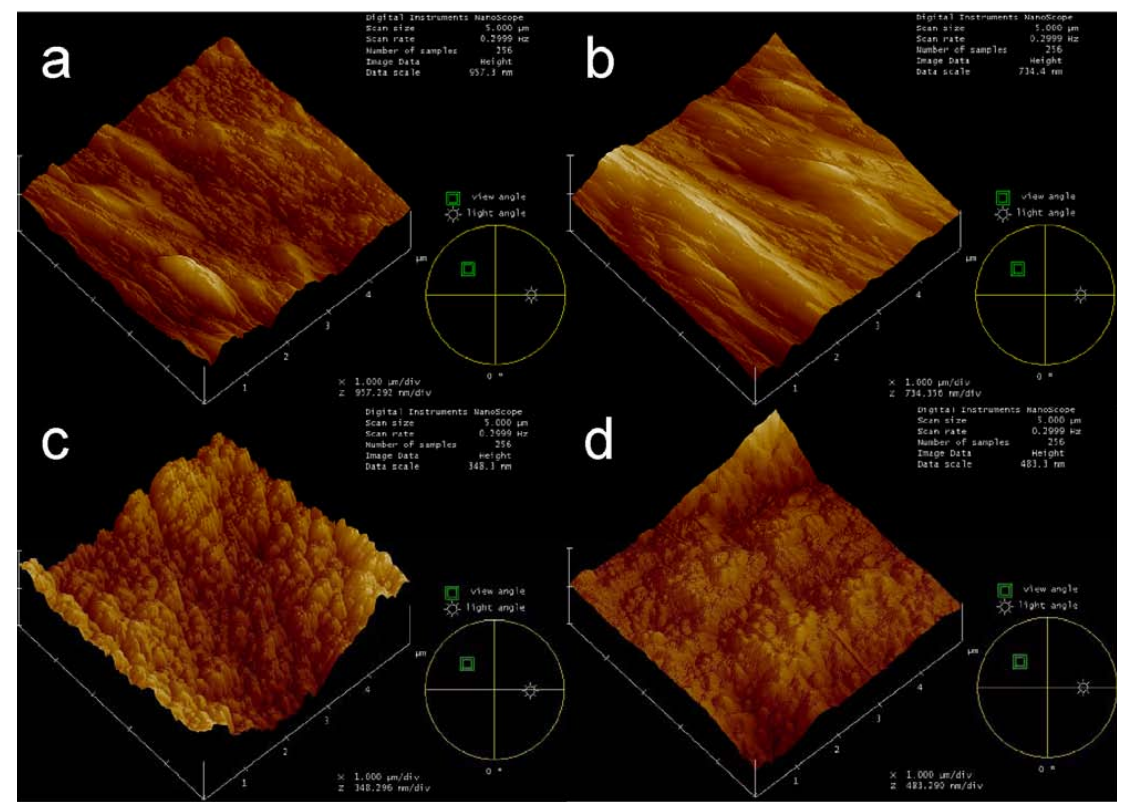

Fig. 1. AFM images of $5 \times 5 \mu \mathrm{m}$ area of non-treated (a) and treated cementum surface with $\mathrm{H} 3 \mathrm{PO} 4$ (b), SEB (c) and OUB (d).
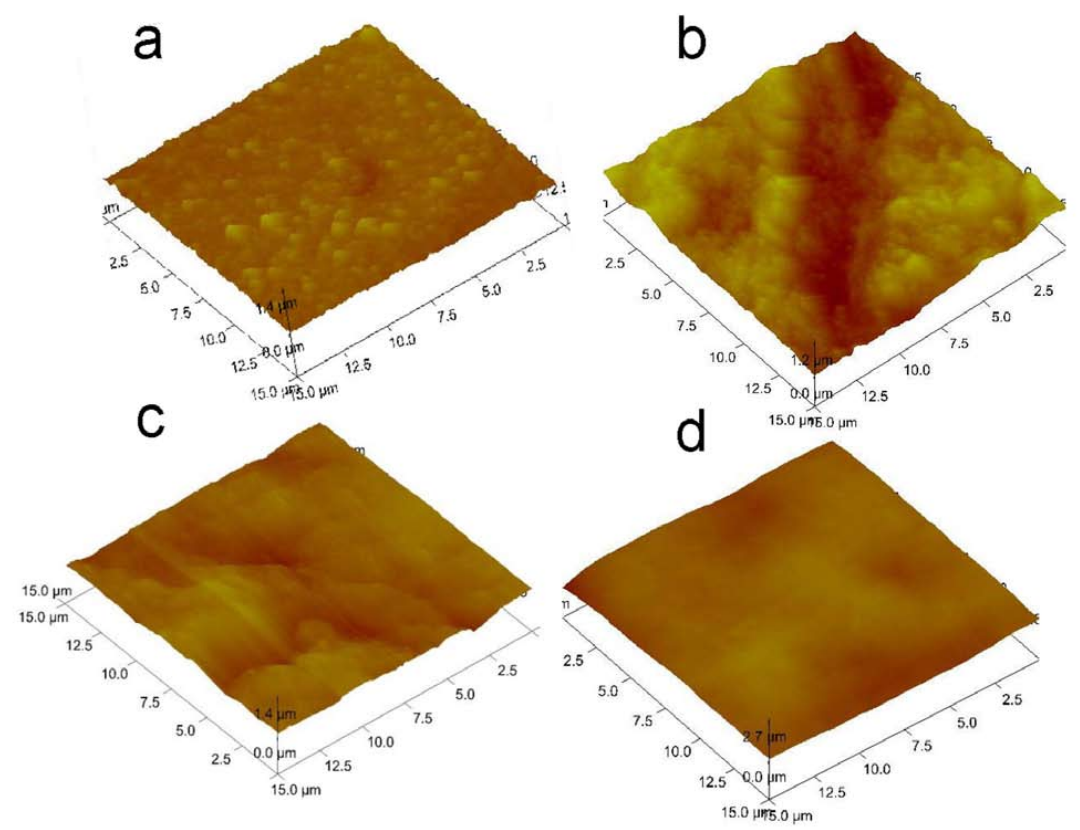

Fig. 2. AFM images of $15 \times 15 \mu \mathrm{m}$ area of non-treated (a) and treated cementum surface with $\mathrm{H} 3 \mathrm{PO} 4(\mathrm{~b})$, SEB (c) and OUB (d). 


\section{Discussion}

In this study, the results require the rejection of the null hypothesis that surface treatments do not change the surface roughness and topography of dental cementum. Despite morphological differences between cementum, dentin and bone, they are composed mainly of collagen and hydroxiapatite (5). Generally, cementum is least mineralized when compared to the others hard tissues: enamel, dentin and bone (15), and is less hard and more permeable compared with enamel and dentin (6).

In Adhesive Dentistry, a rough substrate offers an increased contact surface that means the best micromechanical retention of the system substrate-adhesive (16). In this study, roughness of cementum was increased with phosphoric acid treatment (Table 2). The strong etching effect of phosphoric acid totally removes mineral crystals and exposes denude collagen fibers (3). The minute size of the mineral crystals compared with enamel results in a much larger specific surface area of the mineral component (1). As a consequence, cementum has a more readily to be decalcified in the presence of acidic conditions (1). Also, the lower mineral content and the higher porosity of cementum compared with that of dentin contributed to deeper penetration of the acidic solutions (6). In addition, it appears that the collagen fibers in the cementum may in part accelerate the penetration of etching solutions (2). These reasons indicate that the cementum was more susceptible to acid etching than other dental tissues $(1,2)$.

When self-etching adhesive systems were used as surface treatment, the roughness values were lower than the phosphoric acid group. It is possible that the penetration of the resin components was not homogeneous within the whole thickness of the demineralized cementum layers (6). The adhesive agents used in this study (SEB primer and OUB) contains HEMA. This molecule promotes homogeneous diffusion of various hydrophilic and hydrophobic adhesive monomers within the adhesive itself and into the etched substrates (17). Nevertheless, resin penetration usually occurs around the circumference of the collagen fibers (2). The coarse collagen bundles in the strongly etched cementum may have hampered the penetration of the resin monomers (18). In this treated substrate some water is left even after the drying process (2), which is due in part, to the presence of proteoglycans in the cementum structure (7).

In our study, the AFM images of $5 \times 5 \mu \mathrm{m}$ and the $15 \times 15$ $\mu \mathrm{m}$ have shown similar roughness results. Both of them have demonstrated that $\mathrm{H} 3 \mathrm{PO} 4$ etching group exhibit the highest roughness, but only $15 \times 15 \mu \mathrm{m}$ images was able to detect differences between the other groups. The most recent high-resolution microscopy tool, AFM, in theory, allows imaging up to atomic level (19). The roughness is scale-dependent. The differences appear when a larger area is studied $(20,21)$. Therefore, depending on the field size discrepancies would be different.

The differences in the roughness of cementum surfaces treated for the two self-etching adhesive systems (at $15 \times 15 \mu \mathrm{m}$ scan size) reflected the demineralization ability produced by different composition, application mode and $\mathrm{pH}$ values of each material. Even when cementum surface roughness, after SEB primer application $(\mathrm{pH}=2.1)$, was lower than in the phosphoric etched group, the treated cementum with this primer showed an intermediate etching pattern (Fig. 2c) between H3PO4 and OUB. These moderate roughness values are compatible with a higher performance, as has been previously reported $(3,4,22)$, by the chemical interaction between SEB and human dentin that is able to enhance the bonding mechanism (23). Roughness was drastically decreased after OUB was used, at $15 \times 15 \mu \mathrm{m}$ scan size (Table 2). The lowest roughness of this one-step selfetch bonding agent $(\mathrm{pH}=1.3)$ may be associated with: (a) the combination of acids, hydrophilic and hydrophobic monomers into a single solution may compromise the function of each one of these components $(8,24)$; (b) the differential infiltration due to the phase separation of sparingly water-soluble resin components $(10,25)$, more important when the substrate may contain high concentrations of water remaining $(2,7)$; and (c) the fluoroaminosilicate glass filler contained in the blend might affect the depth of demineralization in a region with thick collagen fibers (3).

\section{Conclusions}

This study demonstrated that phosphoric acid etching enhances the roughness values of the cementum surface. The nanoroughness means of Clearfil SE Bond and One Up Bond F is scale-dependent and increases when a larger area is studied. Only the $15 \times 15 \mu \mathrm{m}$ images was able to detect that OUB shown the lowest roughness.

\section{References References with links to Crossref-DOI}

1. Bosshardt DD, Selvig KA. Dental cementum: the dynamic tissue covering of the root. Periodontol 2000. 1997;13:41-75.

2. Kikushima D, Shimada Y, Foxton RM, Tagami J. Micro-shear bond strength of adhesive systems to cementum. Am J Dent. 2005;18:364-8.

3. Yuan Y, Shimada Y, Ichinose S, Tagami J. Hybridization quality in cervical cementum and superficial dentin using current adhesives. Dent Mater. 2008;24:584-93.

4. Osorio E, Toledano M, da Silveira BL, Osorio R. Effect of different surface treatments on In-Ceram Alumina roughness. An AFM study. J Dent. 2010;38:118-22.

5. Tanaka S, Sugaya T, Kawanami M, Nodasaka Y, Yamamoto T, Noguchi H, et al. Hybrid layer seals the cementum/4-META/ MMA-TBB resin interface. J Biomed Mater Res B Appl Biomater. 2007;80:140-5.

6. Kaneshiro AV, Imazato S, Ebisu S, Tanaka S, Tanaka Y, Sano H. Effects of a self-etching resin coating system to prevent demineralization of root surfaces. Dent Mater. 2008;24:1420-7.

7. Ho SP, Balooch M, Goodis HE, Marshall GW, Marshall SJ. Ul- 
trastructure and nanomechanical properties of cementum dentin junction. J Biomed Mater Res A. 2004 ;68:343-51.

8. Proença JP, Polido M, Osorio E, Erhardt MC, Aguilera FS, GarcíaGodoy F, et al. Dentin regional bond strength of self-etch and totaletch adhesive systems. Dent Mater. 2007;23:1542-8.

9. Tay FR, Pashley DH. Aggressiveness of contemporary self-etching systems. I: Depth of penetration beyond dentin smear layers. Dent Mater. 2001;17:296-308.

10. Toledano M, Osorio R, Osorio E, Aguilera FS, Yamauti M, Pashley DH, et al. Durability of resin-dentin bonds: effects of direct/ indirect exposure and storage media. Dent Mater. 2007;23:885-92.

11. Fawzy AS, Amer MA, El-Askary FS. Sodium hypochlorite as dentin pretreatment for etch-and-rinse single-bottle and two-step self-etching adhesives: atomic force microscope and tensile bond strength evaluation. J Adhes Dent. 2008;10:135-44.

12. Osorio R, Aguilera FS, Otero PR, Romero M, Osorio E, GarcíaGodoy F, et al. Primary dentin etching time, bond strength and ultrastructure characterization of dentin surfaces. J Dent. 2010;38:22231.

13. Kinney JH, Balooch M, Marshall SJ, Marshall GW Jr, Weihs TP. Atomic force microscope measurements of the hardness and elasticity of peritubular and intertubular human dentin. J Biomech Eng. 1996;118:133-5.

14. Pashley DH, Tay FR. Aggressiveness of contemporary self-etching adhesives. Part II: etching effects on unground enamel. Dent Mater. 2001;17:430-44.

15. Ho SP, Goodis H, Balooch M, Nonomura G, Marshall SJ, Marshall G. The effect of sample preparation technique on determination of structure and nanomechanical properties of human cementum hard tissue. Biomaterials. 2004;25:4847-57.

16. Toledano M, Osorio R, Perdigao J, Rosales JI, Thompson JY, Cabrerizo-Vilchez MA. Effect of acid etching and collagen removal on dentin wettability and roughness. J Biomed Mater Res. 1999;47:198203.

17. Spencer P, Wang Y. Adhesive phase separation at the dentin interface under wet bonding conditions. J Biomed Mater Res. 2002;62:447-56.

18. Tay FR, Pashley DH, Yoshiyama M. Two modes of nanoleakage expression in single-step adhesives. J Dent Res. 2002;81:472-6.

19. Yoshida Y, Van Meerbeek B, Snauwaert J, Hellemans L, Lambrechts P, Vanherle G, et al. A novel approach to AFM characterization of adhesive tooth-biomaterial interfaces. J Biomed Mater Res. 1999;47:85-90.

20. Leitão J. Surface roughness and porosity of dental amalgam. Acta Odontol Scand. 1982;40:9-16.

21. Tholt de Vasconcellos B, Miranda-Júnior WG, Prioli R, Thompson J, Oda M. Surface roughness in ceramics with different finishing techniques using atomic force microscope and profilometer. Oper Dent. 2006;31:442-9.

22. Erhardt MC, Osorio R, Pisani-Proenca J, Aguilera FS, Osorio E, Breschi L, et al. Effect of double layering and prolonged application time on MTBS of water/ethanol-based self-etch adhesives to dentin. Oper Dent. 2009;34:571-7.

23. Nunes TG, Polido M, Amorim A, Nunes SG, Toledano M. Multinuclear magnetic resonance studies on the chemical interaction of a self-etching adhesive with radicular and coronal human dentin. J Mater Sci Mater Med. 2007;18:2093-9.

24. Tay FR, Pashley DH, Garcìa-Godoy F, Yiu CK. Single-step, self-etch adhesives behave as permeable membranes after polymerization. Part II. Silver tracer penetration evidence. Am J Dent. 2004;17:315-22.

25. Yiu CK, King NM, Pashley DH, Suh BI, Carvalho RM, Carrilho $\mathrm{MR}$, et al. Effect of resin hydrophilicity and water storage on resin strength. Biomaterials. 2004;25:5789-96.

\section{Acknowledgments}

This work was supported by grants CICYT/FEDER MAT200802347/MAT, JA-P07-CTS2568 and JA-P08-CTS-3944. 